ISSN 2087-3336 (Print) | 2721-4729 (Online)

TEKNOSAINS: Jurnal Sains, Teknologi dan Informatika

Volume 8, Nomor 1, Januari 2021, hlm. 10-22

http://jurnal.sttmcileungsi.ac.id/index.php/tekno

DOI: 10.37373

\title{
USULAN PERBAIKAN MELALUI PENERAPAN TOTAL PRODUCTIVE MAINTENANCE DENGAN METODE OEE PADA MESIN TWIN SCREW EXTRUDER PVC DI PT. XYZ
}

\section{PROPOSED IMPROVEMENT THROUGH THE IMPLEMENTATION OF TOTAL PRODUCTIVE MAINTENANCE WITH OEE METHOD ON TWIN SCREW EXTRUDER PVC MACHINE AT PT. XYZ}

\author{
T Budi Agung, Miftahul Imtihan*, Suwaryo Nugroho \\ Program Studi Teknik Industri, Sekolah Tinggi Teknologi Muhammadiyah Cileungsi, Bogor, Jawa Barat- \\ Indonesia 16820
}

"Koresponden email: miftahul@sttmcileungsi.ac.id

\begin{abstract}
ABSTRAK
Perawatan pada esensinya untuk mengurangi atau meminimalisir kerusakan pada mesin atau peralatan, yang berakibat pada penurunan hasil produksi. Keberlangsungan produktivitas proses produksi dapat ditentukan dengan indikator tingkat OEE. PT. XYZ sebuah perusahaan manufaktur yang menggunakan mesin twin screw extruder. Berdasarkan temuan di lapangan, bahwa selama proses produksi 12 bulan mesin ini seringkali mengalami isu terkait six big losses sehingga mengurangi tingkat availability, performance dan quality. Tujuan dari penelitian ini adalah memberikan usulan perbaikan pemeliharaan mesin secara preventif dan berkala sehingga kerusakan mesin mampu meminimalisir secara optimal. Metode yang diterapkan dalam mencapai target yaitu dengan menerapkan TPM (Total productive maintenance) melalui pendekatan metode OEE (Overall equipment effectiveness) dan analisis fishbone. Temuan dari data-data produksi ditemukan banyaknya isu terkait quality dan rework, dengan temuan defect rata-rata $12 \%$, tingkat scrap rata-rata $2 \%$ dan tingkat rework rata-rata 6\%. Dari hasil analisis perhitungan nilai rata-rata OEE pada mesin twin screw extruder PVC di PT. XYZ adalah 63.10\% yang berarti masih jauh dari standar world class $85 \%$, dengan deviasi sekitar (21.90\%). Hal ini mengindikasikan masih adanya ruang improvement dan perbaikan yang harus dilakukan. Sedangkan dari indikator utama yang berpengaruh terhadap nilai OEE adalah equipment failure dengan kisaran $2502.50 \mathrm{jam}$, dan dari hasil diskusi terhadap analisis fishbone disimpulkan bahwa aspek metode merupakan yang paling berperan terhadap equipment failure tersebut perlunya beberapa usulan perbaikan guna memperbaiki tingkat OEE.
\end{abstract}

Kata Kunci: TPM, OEE, mesin, world class.

\section{ABSTRACT}

Maintenance is essentially to reduce or minimize damage to machines or equipment, which results in reduced production yields. The continuity of the productivity of the production process can be determined by the OEE level indicator. PT. XYZ is a manufacturing company that uses a twin-screw extruder. Based on the findings in the field, that during the 12-month production process, this machine 
often experiences issues related to six big losses, thereby reducing availability, performance, and quality. The purpose of this research is to propose to improve the maintenance of machines in a preventive and periodic manner so that machine damage can be minimized optimally. The method applied in achieving the target is by applying TPM (Total productive maintenance) through the OEE (Overall equipment effectiveness) method approach and fishbone analysis. The findings from the production data show that there are many issues related to quality and rework, with an average defect finding of $12 \%$, an average scrap rate of $2 \%$, and an average rework rate of $6 \%$. From the results of the analysis of the calculation of the average value of OEE on a PVC twin screw extruder at PT. XYZ is $63.10 \%$ which means it is still far from the world-class standard of $85 \%$, with a deviation of around (21.90\%). This indicates that there is still room for improvement and improvements that need to be made. Meanwhile, the main indicator that affects the OEE value is equipment failure with a range of 2502.50 hours, and from the results of the discussion on fishbone analysis, it is concluded that the method aspect is the most influential on the equipment failure. There is a need for some improvement suggestions to improve the OEE level.

Keywords: TPM, OEE, machine, world-class.

\section{PENDAHULUAN}

Dalam industri manufaktur yang menuntut tingkat produktivitas tinggi, maka kontrol dan pengawasan terhadap tingkat downtime merupakan hal yang mutlak dalam menjaga tingkat availability dan performance mesin. Esensi lain dari aktivitas perawatan adalah kegiatan yang dilakukan untuk menjaga atau mempertahankan kualitas mesin-peralatan sehingga mampu berfungsi secara baik. TPM dalam hal ini adalah sebuah pendekatan holistik untuk pemeliharaan peralatan yang berupaya mencapai proses produksi yang mendekati sempurna. [1] Untuk menilai dan memperbaiki kebijakan pemeliharaan hendaknya berdasarkan pada TPM. [2] Salah satu cara untuk meningkatkan kinerja produksi yaitu melalui penerapan TPM.[3] Pentingnya TPM yang digunakan sebagai alat lean manufacturing dalam konteks industri 4.0. [4] Tujuan TPM adalah meminimalisasi kerugian dari sistem manufaktur sehingga mengurangi biaya produksi dengan melakukan pendekatan OEE. [5] Hasil analisis mengungkapkan bahwa inisiatif pemeliharaan tradisional dan inisiatif implementasi TPM secara signifikan mempengaruhi kinerja manufaktur, tetapi tidak mempengaruhi kepemimpinan manajemen puncak serta divisi pemeliharaan.[6] Ketika berproduksi masalah yang sering muncul adalah downtime, breakdown, setup and adjustment yang mengakibatkan produktivitas hasil produksi berkurang.[7] Pada penelitian lain bahwa rendahnya nilai OEE yang diperoleh dari suatu mesin disebabkan atas empat faktor; pengetahuan operator ( $\mathrm{man}$ ) yang kurang tentang mesin, suhu lem yang tidak stabil (machine), pemasok (material) yang terlambat dan waktu penggantian pemotong (method) yang tidak efisien. [8] Perawatan mesin bertujuan untuk mengurangi atau menghindari kerusakan pada mesin atau peralatan dengan metode OEE [9]. OEE merupakan suatu ukuran penggunaan peralatan yang diketahui, mencakup ketersediaan, kualitas, serta kinerja aliran produksi [10]. OEE dapat membantu perusahaan mengidentifikasi persoalan utama terkait adanya ketersediaan serta efisiensi kinerja.[11] Pengukuran OEE sering kali menjadi bagian sentral dan alasan penting untuk investasi. [12] Kerugian efisiensi operasional ditemukan memiliki dampak terbesar pada OEE yang diikuti oleh kerugian ketersediaan.[13] Pada penggunaan metode OEE yang dilanjutkan dengan perhitungan OEE six big losses dapat mengetahui besarnya efisiensi yang hilang pada masing-masing faktor six big losses [14]. Enam six big losses utama terkait OEE, yaitu kegagalan mesin dan proses, set up adjustment dan penyesuaian mesin, penghentian kecil di sela proses, reduced speed/ pengurangan kecepatan, cacat dalam proses, dan produk tidak lolos QC. pengurangan hasil di tempat pertama, diperiksa dengan bantuan analisis pareto, dan analisis sebab-akibat (fishbone.[15] OEE digunakan untuk mengetahui nilai efektivitas mesin dan penyebab masalah yang dapat diselesaikan dengan 
menggunakan FMEA.[16] Alat yang berharga untuk membangun dan memelihara keandalan sistem, keseluruhan efektivitas peralatan (OEE) telah terbukti sangat efektif dalam mengurangi waktu henti yang tidak terjadwal untuk perusahaan di seluruh dunia. [17] PT. XYZ adalah sebuah perusahaan manufaktur yang menggunakan mesin twin screw extruder. Berdasarkan temuan di lapangan, data catatan maintenance dan data-data produksi selama 12 bulan, mesin ini seringkali mengalami isu terkait six big losses sehingga mengurangi tingkat availability, performance dan quality. Tujuan dari penelitian ini adalah memberikan usulan perbaikan pemeliharaan mesin secara preventive dan berkala sehingga kerusakan mesin mampu meminimalisir secara optimal. Metode yang diterapkan dalam mencapai target yaitu dengan menerapkan TPM (Total productive maintenance) melalui pendekatan metode OEE (overall equipment effectiveness).

\section{METODE}

Metode yang digunakan dalam penelitian ini terdiri dari beberapa tahapan, mencakup; 1). Metode literatur; yaitu melakukan tinjauan berbagai literatur yang sesuai sebagai dasar penelitian terkait permasalahan yang terjadi utamanya tentang penerapan TPM, OEE dan beberapa jurnal penelitian yang relevan sebelumnya; 2). Pengumpulan data; adalah melakukan pengumpulan data melalui tinjauan lapangan secara langsung untuk memperoleh data-data pokok yang meliputi data produksi, defect, scrap, rework serta data penunjang lainnya; 3). Assessment tingkat OEE; yaitu melakukan penilaian dan perhitungan terhadap kondisi tingkat OEE existing; 4). analisis dan usulan perbaikan; melakukan analisis untuk mencari akar masalah, dan memberikan usulan-usulan perbaikan yang harus dilakukan; 5). Kesimpulan; membuat kesimpulan terhadap proses tahapan keseluruhan penelitian, Untuk memperjelas, kerangka penelitian yang dimaksud.

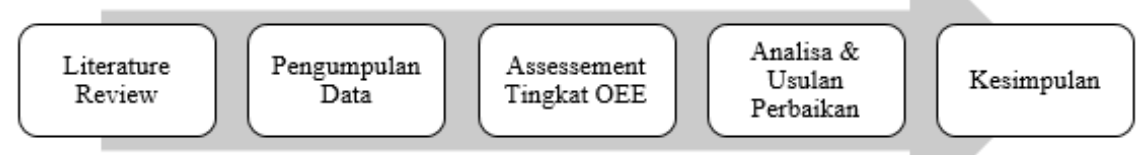

Gambar 1. Kerangka penelitian.

\section{HASIL DAN PEMBAHASAN}

3.1 Data hasil produksi pipa PVC.

Berdasarkan data sekunder dari divisi produksi pipa PVC PT. XYZ sejak bulan Januari-Desember tahun 2019, diketahui bahwa selama proses produksi berjalan pada periode bulan tersebut ditemukan banyaknya isu terkait quality dan rework, dengan nilai defect rata-rata selama 12 bulan adalah $12 \%$, tingkat scrap rata-rata $2 \%$ dan tingkat rework rata-rata 6\%. Defect tertinggi terjadi pada bulan November yaitu sebesar 26\%, yang dijelaskan pada tabel 1 .

Tabel 1. Data produksi pipa PVC.

\begin{tabular}{|c|c|c|c|c|c|c|c|c|c|c|}
\hline \multirow{2}{*}{ Bulan } & \multirow{2}{*}{$\begin{array}{c}\text { Rencana } \\
\text { produksi } \\
\text { (kg) }\end{array}$} & \multirow{2}{*}{$\begin{array}{c}\text { Aktual } \\
\text { produksi } \\
(\mathbf{k g})\end{array}$} & \multicolumn{2}{|c|}{ Defect } & \multicolumn{2}{|c|}{ Scrap } & \multicolumn{2}{|c|}{ Rework } & \multicolumn{2}{|c|}{$\begin{array}{c}\text { Total quality } \\
\text { issue }\end{array}$} \\
\hline & & & (kg) & $(\%)$ & $(\mathrm{kg})$ & $(\%)$ & $(\mathrm{kg})$ & $(\%)$ & $(\mathrm{kg})$ & $(\%)$ \\
\hline Janu & 142.851 & 129.370 & 13.480 & $10 \%$ & 2.696 & $2 \%$ & 10.784 & $8 \%$ & 26.960 & $21 \%$ \\
\hline Februari & 84.529 & 72.791 & 11.737 & $16 \%$ & 2.347 & $3 \%$ & 939 & $1 \%$ & 15.023 & $21 \%$ \\
\hline Maret & 88.973 & 83.586 & 5.387 & $6 \%$ & 1.077 & $1 \%$ & 4.309 & $5 \%$ & 10.773 & $13 \%$ \\
\hline April & 116.259 & 105.521 & 10.738 & $10 \%$ & 2.147 & $2 \%$ & 859 & $1 \%$ & 13.744 & $13 \%$ \\
\hline
\end{tabular}




\begin{tabular}{ccccccccccc} 
Mei & 114.646 & 106.646 & 8.000 & $8 \%$ & 1.600 & $2 \%$ & 64 & $0 \%$ & 9.664 & $9 \%$ \\
Juni & & & - & - & - & - & - & - & - & - \\
Juli & 172.065 & 140.555 & 31.509 & $22 \%$ & 6.301 & $4 \%$ & 25.207 & $18 \%$ & 63.017 & $45 \%$ \\
Agustus & 64.248 & 60.185 & 4.063 & $7 \%$ & 812 & $1 \%$ & 325 & $1 \%$ & 5.200 & $9 \%$ \\
September & 119.442 & 114.521 & 4.921 & $4 \%$ & 984 & $1 \%$ & 3.937 & $3 \%$ & 9.842 & $9 \%$ \\
Oktober & 114.794 & 97.619 & 17.175 & $18 \%$ & 3.435 & $4 \%$ & 1.374 & $1 \%$ & 21.984 & $23 \%$ \\
November & 107.128 & 85.019 & 22.109 & $26 \%$ & 4.421 & $5 \%$ & 17.687 & $21 \%$ & 44.217 & $52 \%$ \\
Desember & 128.238 & 122.809 & 5.429 & $4 \%$ & 1.085 & $1 \%$ & 4.343 & $4 \%$ & 10.857 & $9 \%$ \\
\hline
\end{tabular}

3.2 Perhitungan OEE machine twin screw extruder.

A. Perhitungan availability.

Availability merupakan gambaran dari suatu rasio penggunaan waktu yang tersedia untuk kegiatan operasi suatu mesin-peralatan. Ada 2 komponen yang mempengaruhi availability yaitu equipment failure dan set-up dan adjustment. Proses perhitungan availability bulan Januari.

Availability $=\frac{\text { Loading Time }- \text { Downtime }}{\text { Loading } \text { Time }} \times 100 \%$

Availability $=\frac{744-25}{744} \times 100 \%=96.64 \%$

Dengan menggunakan metode yang sama, dilakukan dalam perhitungan per bulan diperoleh nilai availability yang dijelaskan tabel 2.

Tabel 2. Data perhitungan availability.

\begin{tabular}{cccc}
\hline Bulan & $\begin{array}{c}\text { Loading } \\
\text { time }\end{array}$ & $\begin{array}{c}\text { Down } \\
\text { time }\end{array}$ & Availability \\
\hline Januari & 744 & 25 & $\mathbf{9 6 . 6 4 \%} \%$ \\
Febuari & 672 & 208 & $69.05 \%$ \\
Maret & 744 & 202 & $72.85 \%$ \\
April & 720 & 110 & $84.72 \%$ \\
Mei & 744 & 35 & $95.30 \%$ \\
Juni & 0 & 0 & $0.00 \%$ \\
Juli & 744 & 90 & $87.97 \%$ \\
Agustus & 744 & 278 & $62.63 \%$ \\
September & 720 & 42 & $94.24 \%$ \\
Oktober & 744 & 125 & $83.20 \%$ \\
November & 720 & 54 & $92.50 \%$ \\
Desember & 744 & 94 & $87.37 \%$ \\
\hline
\end{tabular}

B. Perhitungan Performance Efficiency.

Performance efficiency merupakan rasio yang menggambarkan kemampuan suatu peralatan atau mesin untuk dapat menghasilkan suatu output atau produk. Ada 2 komponen yang mempengaruhi performance efficiency yaitu reduce speed dan idling and minor stoppage.

Waktu siklus $=\frac{\text { Loading Time }}{\text { Total produksi }}$

Waktu siklus $=\frac{744}{142851}=0,0052 \mathrm{jam} / \mathrm{kg}$

Waktu siklus $=$ waktu siklus $\times \%$ Jam kerja

Waktu siklus $=0.0052 \times 92.74 \%=0.0048 \mathrm{jam} / \mathrm{kg}$ 
T Budi Agung, Miftahul Imtihan, Suwaryo Nugroho

USULAN PERBAIKAN MELALUI PENERAPAN TOTAL PRODUCTIVE

MAINTENANCE DENGAN METODE OEE PADA MESIN TWIN SCREW EXTRUDER

PVC DI PT. XYZ

Dengan menggunakan metode yang sama, dilakukan dalam perhitungan per bulan diperoleh nilai $\%$ jam kerja dan idle cycle time pada tabel 3.

Tabel 3. Perhitungan \% jam kerja dan idle cycle time.

\begin{tabular}{cccccc}
\hline Bulan & $\begin{array}{c}\text { Produksi } \\
(\boldsymbol{a})\end{array}$ & $\begin{array}{c}\text { Loading } \\
\text { time }(\boldsymbol{b})\end{array}$ & $\begin{array}{c}\text { Cycle time } \\
(\boldsymbol{c})=(\boldsymbol{b}) /(\boldsymbol{a})\end{array}$ & $\begin{array}{c}\text { \% Jam } \\
\text { Kerja }(\boldsymbol{d})\end{array}$ & $\begin{array}{c}\text { Idle cycle } \\
\text { time }(\boldsymbol{e})\end{array}$ \\
\hline Januari & $142,851.00$ & 744 & 0.0052 & 92.74 & $\mathbf{0 . 0 0 4 8 \%} \%)$ \\
Februari & $84,529.00$ & 672 & 0.0079 & 63.24 & $0.0050 \%$ \\
Maret & $88,973.00$ & 744 & 0.0084 & 66.73 & $0.0056 \%$ \\
April & $116,259.00$ & 720 & 0.0062 & 78.19 & $0.0048 \%$ \\
Mei & $114,646.00$ & 744 & 0.0065 & 60.22 & $0.0039 \%$ \\
Juni & - & - & - & - & - \\
Juli & $172,065.00$ & 744 & 0.0043 & 53.43 & $0.0023 \%$ \\
Agustus & $64,248.50$ & 744 & 0.0116 & 50.13 & $0.0058 \%$ \\
September & $119,442.50$ & 720 & 0.0060 & 84.24 & $0.0051 \%$ \\
Oktober & $114,794.00$ & 744 & 0.0065 & 77.55 & $0.0050 \%$ \\
November & $107,128.00$ & 720 & 0.0067 & 84.14 & $0.0057 \%$ \\
Desember & $128,238.50$ & 744 & 0.0058 & 46.77 & $0.0027 \%$ \\
\hline
\end{tabular}

Performance Efficiency $=\frac{\text { Process Amount } x \text { Ideal Cycle Time }}{\text { Operation Time }} \times 100 \%$

Performance Efficiency $=\frac{129370.5 \times 0.0048}{690} \times 100 \%=90.00 \%$

Dengan menggunakan metode yang sama diperoleh nilai performance efficiency bulan JanuariDesember yang dijelaskan pada tabel 4 .

Tabel 4. Perhitungan performance efficiency.

\begin{tabular}{crccc}
\hline Bulan & $\begin{array}{c}\text { Aktual } \\
\text { produksi }\end{array}$ & Idle cycle time & $\begin{array}{c}\text { Operation } \\
\text { time }\end{array}$ & $\begin{array}{c}\text { Performance } \\
\text { efficiency }\end{array}$ \\
\hline Januari & $129,370.50$ & 0.0048 & 690 & $\mathbf{9 0 . 0 0 * )}$ \\
Februari & $72,791.50$ & 0.0050 & 425 & 85.64 \\
Maret & 83,586 & 0.0056 & 496.5 & 94.28 \\
April & 105,521 & 0.0048 & 563 & 89.96 \\
Mei & 106,646 & 0.0039 & 422 & 98.56 \\
Juni & & - & - & - \\
Juli & 140555.5 & 0.0023 & 276 & 117.13 \\
Agustus & 60,185 & 0.0058 & 373 & 93.59 \\
September & 114,521 & 0.0051 & 622 & 93.90 \\
Oktober & 97,619 & 0.005 & 577 & 84.59 \\
November & 85,019 & 0.0057 & 613 & 79.06 \\
Desember & 122,809 & 0.0027 & 352 & 94.20 \\
\hline
\end{tabular}

C. Proses menghitung quality rate.

Quality rate merupakan rasio penggambaran kemampuan mesin-peralatan untuk menghasilkan produk secara standar yang telah ditentukan. Ada 2 komponen yang mempengaruhi quality rate yaitu defect in process dan reduce yield. Rumus yang digunakan untuk mengukur quality rate. 
Quality Rate $=\frac{\text { Process Amount }- \text { Deffect Amount }}{\text { Process Amount }} \times 100 \%$

Quality Rate $=\frac{129370.50-13480.50}{129370.50} \times 100 \%=89.58 \%$

Dengan menggunakan metode yang sama diperoleh nilai quality rate bulan Januari-Desember, pada tabel 5 .

Tabel 5. Perhitungan quality rate.

\begin{tabular}{cccc}
\hline Bulan & Aktual Produksi & Defect & Quality Rate \\
\hline Januari & $129,370.50$ & $13,480.50$ & $\mathbf{8 9 . 5 8 * )}$ \\
Februari & $72,791.50$ & $11,737.50$ & 83.88 \\
Maret & 83,586 & $5,387.00$ & 93.56 \\
April & 105,521 & $10,738.00$ & 89.82 \\
Mei & 106,646 & $8,000.00$ & 92.50 \\
Juni & - & - & - \\
Juli & 140555.5 & $31,509.50$ & 77.58 \\
Agustus & 60,185 & $4,063.50$ & 93.25 \\
September & 114,521 & $4,921.50$ & 95.70 \\
Oktober & 97,619 & $17,175.00$ & 82.41 \\
November & 85,019 & $22,109.00$ & 74.00 \\
Desember & 122,809 & $5,429.50$ & 95.58 \\
\hline
\end{tabular}

D. Proses menghitung OEE.

Formula menghitung nilai OEE.

OEE $(\%)=$ availability $(\%) \times$ performance efficiency $(\%) \times$ quality rate $(\%)$

OEE $(\%)=96.64 \times 90.00 \times 89.58=77.91 \%$

Dengan metode yang sama diperoleh OEE bulan Januari-Desember, pada tabel 6 .

Tabel 6. Proses menghitung OEE.

\begin{tabular}{ccccc}
\hline $\begin{array}{c}\text { Periode } \\
\text { Bulan }\end{array}$ & availability & $\begin{array}{c}\text { performance } \\
\text { efficiency }\end{array}$ & $\begin{array}{c}\text { quality } \\
\text { rate }\end{array}$ & OEE \\
\hline Januari & 96.64 & 90.00 & 89.58 & $\mathbf{7 7 . 9 1 \%} *)$ \\
Februari & 69.05 & 85.64 & 83.88 & $49.60 \%$ \\
Maret & 72.85 & 94.28 & 93.56 & $64.26 \%$ \\
April & 84.72 & 89.96 & 89.82 & $68.46 \%$ \\
Mei & 95.30 & 98.56 & 92.50 & $86.88 \%$ \\
Juni & - & - & - & - \\
Juli & 87.97 & 117.13 & 77.58 & $79.94 \%$ \\
Agustus & 62.63 & 93.59 & 93.25 & $54.66 \%$ \\
September & 94.24 & 93.90 & 95.70 & $84.69 \%$ \\
Oktober & 83.20 & 84.59 & 82.41 & $58.00 \%$ \\
November & 92.50 & 79.06 & 74.00 & $54.12 \%$ \\
Desember & 87.37 & 94.20 & 95.58 & $78.66 \%$ \\
\hline Rata-rata & $\mathbf{7 7 . 2 1}$ & $\mathbf{8 5 . 0 8}$ & $\mathbf{8 0 . 6 6}$ & $\mathbf{6 3 . 1 0 \%}$ \\
\hline
\end{tabular}

Tabel 6 menunjukkan bahwa nilai OEE machine twin screw extruder PVC di PT. XYZ 63.10\%, angka hasil ini masih jauh dari standar World Class yaitu 85\%, sehingga masih terdapat deviasi 
T Budi Agung, Miftahul Imtihan, Suwaryo Nugroho

USULAN PERBAIKAN MELALUI PENERAPAN TOTAL PRODUCTIVE

MAINTENANCE DENGAN METODE OEE PADA MESIN TWIN SCREW EXTRUDER

PVC DI PT. XYZ

sekitar (21.90\%). Hal ini mengindikasikan masih adanya ruang improvement dan perbaikan yang harus dilakukan.

3.3 Perhitungan Six Big Losses.

A. Equipment failure (Breakdown).

Kerusakan mesin merupakan faktor yang mempengaruhi mesin-peralatan dalam operasionalnya.

Equipment Failure $=\frac{\text { Total Breakdown }}{\text { Loading Time }} \times 100 \%$

Equipment Failure $=\frac{54}{744} \times 100 \%=7.26 \%$

Dengan menggunakan metode yang sama diperoleh equipment failure bulan Januari-Desember, seperti pada tabel 7 .

Tabel 7. Equipment failure (Breakdown)

\begin{tabular}{cccc}
\hline Bulan & Breakdown & Loading Time & Equipment Failure (\%) \\
\hline Januari & 54.00 & 744 & $\mathbf{7 . 2 6} *)$ \\
Februari & 247.00 & 672 & 36.76 \\
Maret & 247.50 & 744 & 33.27 \\
April & 157.00 & 720 & 21.81 \\
Mei & 296.00 & 744 & 39.78 \\
Juni & 0.00 & 360 & 0.00 \\
Juli & 346.50 & 744 & 46.57 \\
Agustus & 371.00 & 744 & 49.87 \\
September & 113.50 & 720 & 15.76 \\
Oktober & 167.00 & 744 & 22.45 \\
November & 107.00 & 720 & 14.86 \\
Desember & 396.00 & 744 & 53.23 \\
\hline Jumlah & $\mathbf{2 5 0 2 . 5 0}$ & \multicolumn{3}{l}{} \\
\hline
\end{tabular}

B. Proses menghitung set-up and adjustment losses

Set Up \& Adjusment Losses $=\frac{\text { Set Up Adjusment }}{\text { Loading Time }} \times 100 \%$

Set Up \& Adjusment Losses $=\frac{20}{744} \times 100 \%=2.69 \%$

Dengan metode yang sama diperoleh set-up and adjustment losses bulan Januari-Desember, pada tabel 8 .

Tabel 8. Set up and adjustment losses

\begin{tabular}{lccc}
\hline Bulan & $\begin{array}{c}\text { Loading } \\
\text { Time }\end{array}$ & $\begin{array}{c}\text { Set-Up and } \\
\text { Adjustment }\end{array}$ & $\begin{array}{c}\text { Set-Up and Adjustment } \\
\text { Losses }\end{array}$ \\
\hline Januari & 744 & 20 & $\mathbf{2 . 6 9} *)$ \\
Februari & 672 & 31 & 4.61 \\
Maret & 744 & 18.5 & 2.49 \\
April & 720 & 10 & 1.39 \\
Mei & 744 & 19 & 2.55 \\
Juni & 0 & 0 & 0.00
\end{tabular}




\begin{tabular}{lccc} 
Juli & 744 & 29 & 3.90 \\
Agustus & 744 & 17 & 2.28 \\
September & 720 & 32 & 4.44 \\
Oktober & 744 & 29 & 3.90 \\
November & 720 & 22 & 3.06 \\
Desember & 744 & 26.5 & 3.56 \\
\hline Jumlah & & $\mathbf{2 5 4}$ & \\
\hline
\end{tabular}

C. Proses menghitung idling dan minor stoppage losses

$$
\begin{aligned}
& \text { Idling and Miror Stoppage Losses }=\frac{\text { Non Productive Time }}{\text { Loading Time }} \times 100 \% \\
& \text { Idling and Miror Stoppage Losses }=\frac{7}{744} \times 100 \%=0.94 \%
\end{aligned}
$$

Dengan metode yang sama diperoleh idling and minor stoppage losses bulan Januari-Desember, pada tabel 9 .

Tabel 9. Idling and minor stoppage losses

\begin{tabular}{cccc}
\hline Bulan & $\begin{array}{c}\text { Loading } \\
\text { time }\end{array}$ & $\begin{array}{c}\text { Non productive } \\
\text { time }\end{array}$ & $\begin{array}{c}\text { Idling and minor } \\
\text { stoppage losses }\end{array}$ \\
\hline Januari & 744 & 7 & $\mathbf{0 . 9 4} *)$ \\
Februari & 672 & 5 & 0.74 \\
Maret & 744 & 18 & 2.42 \\
April & 720 & 8 & 1.11 \\
Mei & 744 & 8 & 1.08 \\
Juni & 0 & 0 & 0.00 \\
Juli & 744 & 16 & 2.15 \\
Agustus & 744 & 8 & 1.08 \\
September & 720 & 9 & 1.25 \\
Oktober & 744 & 3 & 0.40 \\
November & 720 & 8 & 1.11 \\
Desember & 744 & 8 & 1.08 \\
\hline Jumlah & \multicolumn{3}{|}{} \\
\hline
\end{tabular}

D. Menghitung reduced speed

Reduced Speed Losses $=\frac{\text { operating Time }-(\text { Waktu Siklus Ideal } \times \text { Process Amount })}{\text { Loading Time }} \times 100 \%$

Reduced Speed Losses $=\frac{(0.0048-129370.50)}{744} \times 100 \%=9.27 \%$

Dengan menggunakan metode yang sama diperoleh reduced speed losses bulan JanuariDesember, pada tabel 10.

Tabel 10. Reduced speed losses

\begin{tabular}{cccccc}
\hline Bulan & $\begin{array}{c}\text { Loading } \\
\text { Time }\end{array}$ & $\begin{array}{c}\text { Operating } \\
\text { Time }\end{array}$ & $\begin{array}{c}\text { Ideal Cycle Time } \\
\boldsymbol{X} \text { Total Produk }\end{array}$ & Reduce Speed & $\begin{array}{c}\text { Reduce speed } \\
\text { losses }\end{array}$ \\
\hline Januari & 744 & 690 & 620.98 & 69.02 & $9.27 \% *)$ \\
Februari & 672 & 425 & 365.96 & 59.04 & $8.79 \%$ \\
Maret & 744 & 496.5 & 466.41 & 30.09 & $4.04 \%$ \\
April & 720 & 563 & 510.97 & 52.03 & $7.23 \%$ \\
Mei & 744 & 422 & 416.7 & 5.3 & $0.71 \%$
\end{tabular}


USULAN PERBAIKAN MELALUI PENERAPAN TOTAL PRODUCTIVE MAINTENANCE DENGAN METODE OEE PADA MESIN TWIN SCREW EXTRUDER PVC DI PT. XYZ

\begin{tabular}{cccccc} 
Juni & 0 & 0 & 0 & 0 & $0.00 \%$ \\
Juli & 744 & 407 & 324.66 & 82.34 & $11.07 \%$ \\
Agustus & 744 & 373 & 349.38 & 23.62 & $3.17 \%$ \\
September & 720 & 622 & 581.47 & 40.53 & $5.63 \%$ \\
Oktober & 744 & 577 & 490.65 & 86.35 & $11.61 \%$ \\
November & 720 & 613 & 486.44 & 126.56 & $17.58 \%$ \\
Desember & 744 & 352 & 333.24 & 18.76 & $2.52 \%$ \\
\hline Jumlah & & & $\mathbf{5 9 4}$ & \\
\hline
\end{tabular}

E. Defect in process/rework

Defect in process - Rework $=\frac{\text { Ideal Cyle Time } x \text { Rework }}{\text { Loading Time }} \times 100 \%$

Defect in process - Rework $=\frac{0.0048 \times 10784.40}{744} \times 100 \%=0.07 \%$

Dengan menggunakan metode yang sama diperoleh defect in process-rework bulan JanuariDesember, pada tabel 11.

Tabel 11. Defect in process/rework

\begin{tabular}{|c|c|c|c|c|c|}
\hline Bulan & $\begin{array}{c}\text { Loading } \\
\text { time } \\
\text { (jam) }\end{array}$ & $\begin{array}{l}\text { Ideal Cycle } \\
\text { Time (jam) }\end{array}$ & Rework (kg) & $\begin{array}{l}\text { Rework Time } \\
\text { Losses (Jam) }\end{array}$ & $\begin{array}{c}\text { Defect in process } \\
\text { - Rework }\end{array}$ \\
\hline Januari & 744 & 0.0048 & 10784.40 & 51.77 & $0.07 \% *)$ \\
\hline Februari & 672 & 0.0050 & 9390.00 & 47.23 & $0.07 \%$ \\
\hline Maret & 744 & 0.0056 & 4309.60 & 24.05 & $0.03 \%$ \\
\hline April & 720 & 0.0048 & 8590.40 & 41.23 & $0.06 \%$ \\
\hline Mei & 744 & 0.0025 & 6400.00 & 16 & $0.02 \%$ \\
\hline Juni & 0 & 0 & 0 & 0 & $0.00 \%$ \\
\hline Juli & 744 & 0.0013 & 25207.60 & 32.01 & $0.04 \%$ \\
\hline Agustus & 744 & 0.0058 & 3250.80 & 18.85 & $0.03 \%$ \\
\hline September & 720 & 0.0068 & 39372.00 & 26.69 & $0.37 \%$ \\
\hline Oktober & 744 & 0.0050 & 13740.00 & 69.11 & $0.09 \%$ \\
\hline November & 720 & 0.0057 & 17687.20 & 101.17 & $0.14 \%$ \\
\hline Desember & 744 & 0.0027 & 4343.60 & 11.77 & $0.02 \%$ \\
\hline Jumlah & & & & 439.88 & \\
\hline
\end{tabular}

F. $\quad$ Reduced scrap

Reduced Scrap $=\frac{\text { Ideal Cyle Time } \times \text { Scrap }}{\text { Loading } \text { Time }} \times 100 \%$

Reduced Scrap $=\frac{0.0048 \times 2696.10}{744} \times 100 \%=0.02 \%$

Dengan metode yang sama diperoleh reduced scrap bulan Januari-Desember, pada tabel 12.

Tabel 12. Reduced scrap

\begin{tabular}{cccccc}
\hline Bulan & $\begin{array}{c}\text { Loading } \\
\text { Time }(\mathbf{j a m})\end{array}$ & $\begin{array}{l}\text { Ideal } \\
\text { time }(\mathrm{jam})\end{array}$ & $\begin{array}{l}\text { cycle } \\
(\mathrm{kg})\end{array}$ & $\begin{array}{c}\text { Scrap Time Losses } \\
(\mathbf{j a m})\end{array}$ & Scrap losses \\
\hline Januari & 744 & 0.0048 & 2696.10 & 12.94 & $\mathbf{0 . 0 2 \%} \%)$ \\
Februari & 672 & 0.0050 & 2347.50 & 11.81 & $0.02 \%$
\end{tabular}




\begin{tabular}{cccccc} 
Maret & 744 & 0.0056 & 1077.40 & 6.01 & $0.01 \%$ \\
April & 720 & 0.0048 & 2147.60 & 10.31 & $0.01 \%$ \\
Mei & 744 & 0.0025 & 1600.00 & 4.00 & $0.01 \%$ \\
Juni & 0 & 0 & 0.00 & 0.00 & $0.00 \%$ \\
Juli & 744 & 0.0013 & 6301.90 & 8.00 & $0.01 \%$ \\
Agustus & 744 & 0.0058 & 812.70 & 4.71 & $0.01 \%$ \\
September & 720 & 0.0068 & 984.30 & 6.67 & $0.01 \%$ \\
Oktober & 744 & 0.0050 & 3435.00 & 17.28 & $0.02 \%$ \\
November & 720 & 0.0057 & 4421.80 & 25.29 & $0.04 \%$ \\
Desember & 744 & 0.0027 & 1085.90 & 2.94 & $0.00 \%$ \\
\hline Jumlah & & &
\end{tabular}

\subsection{Time losses}

Berdasarkan hasil perhitungan diatas, maka dapat kita buat dalam bentuk resume six big losses yang berdampak bagi operasional mesin-peralatan produksi, dijelaskan pada tabel 13.

Tabel 13. Time losses dari six big losses

\begin{tabular}{lc}
\hline \multicolumn{1}{c}{ Six Big Losses } & Time Losses (Jam) \\
\hline 1. Equipment Failure (Breakdown) & $\mathbf{2 5 0 2 . 5 0}$ \\
2. Set-up and Adjustment Losses & 254.00 \\
3. Idling and Minor Stoppage Losses & 98.00 \\
4. Reduced Speed & 594.00 \\
5. Defect in process/ Rework & 439.88 \\
6. Reduced Scrap & 109.96 \\
\hline \multicolumn{1}{c}{ Total } & $\mathbf{3 9 9 8 . 3 4}$ \\
\hline
\end{tabular}

Dari data tabel 13 diketahui bahwa equipment failure, faktor yang paling tinggi yang memberikan sumbangsih dalam penurunan tingkat availability mesin. Hal tersebut dapat digambarkan dalam bentuk data pareto time losses dari six big losses, pada gambar 2.

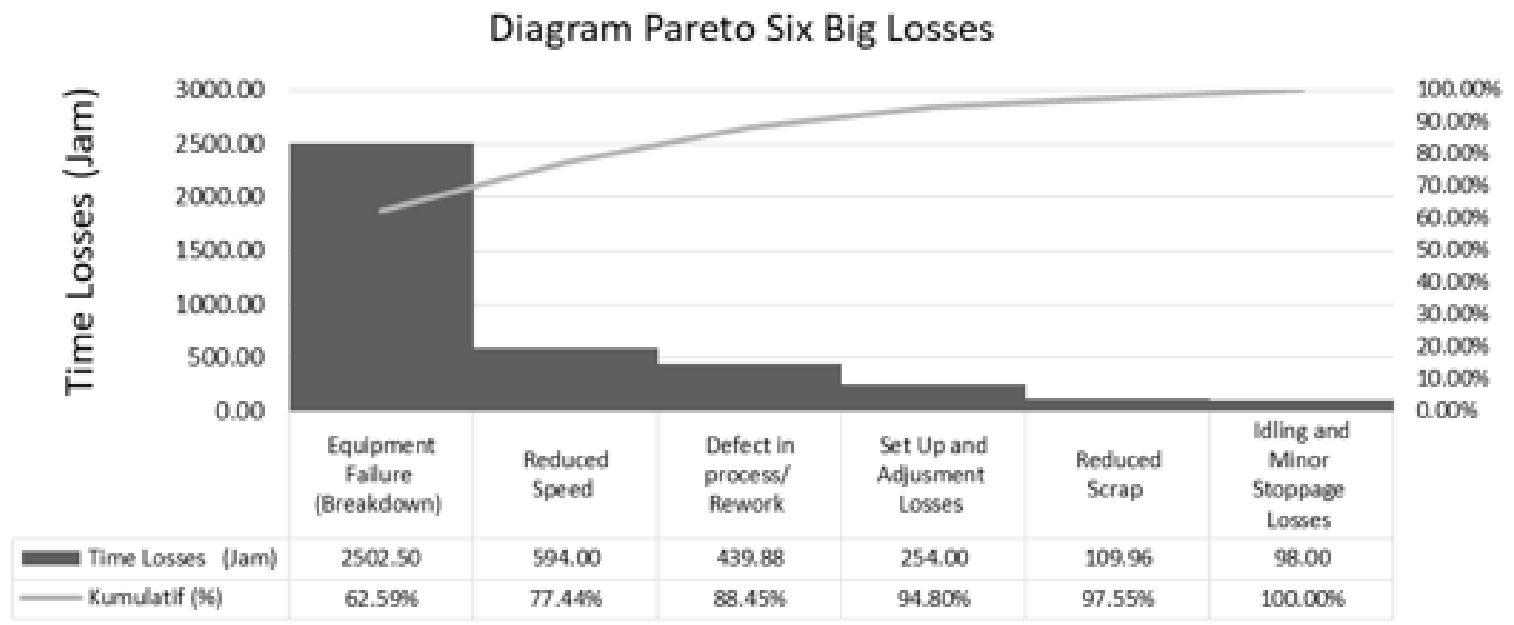

Gambar 2. Pareto time losses dari six big losses

\subsection{Analysis root cause}

Tabel 13 dan gambar 2 menunjukkan bahwa losses tertinggi adalah equipment failure (Breakdown), artinya hal ini merupakan faktor yang mendominasi terhadap kinerja operasional 
USULAN PERBAIKAN MELALUI PENERAPAN TOTAL PRODUCTIVE MAINTENANCE DENGAN METODE OEE PADA MESIN TWIN SCREW EXTRUDER PVC DI PT. XYZ

machine twin screw extruder PVC di PT. XYZ dan oleh karena itu langkah selanjutnya dilakukan fishbone analysis equipment failure (Breakdown).

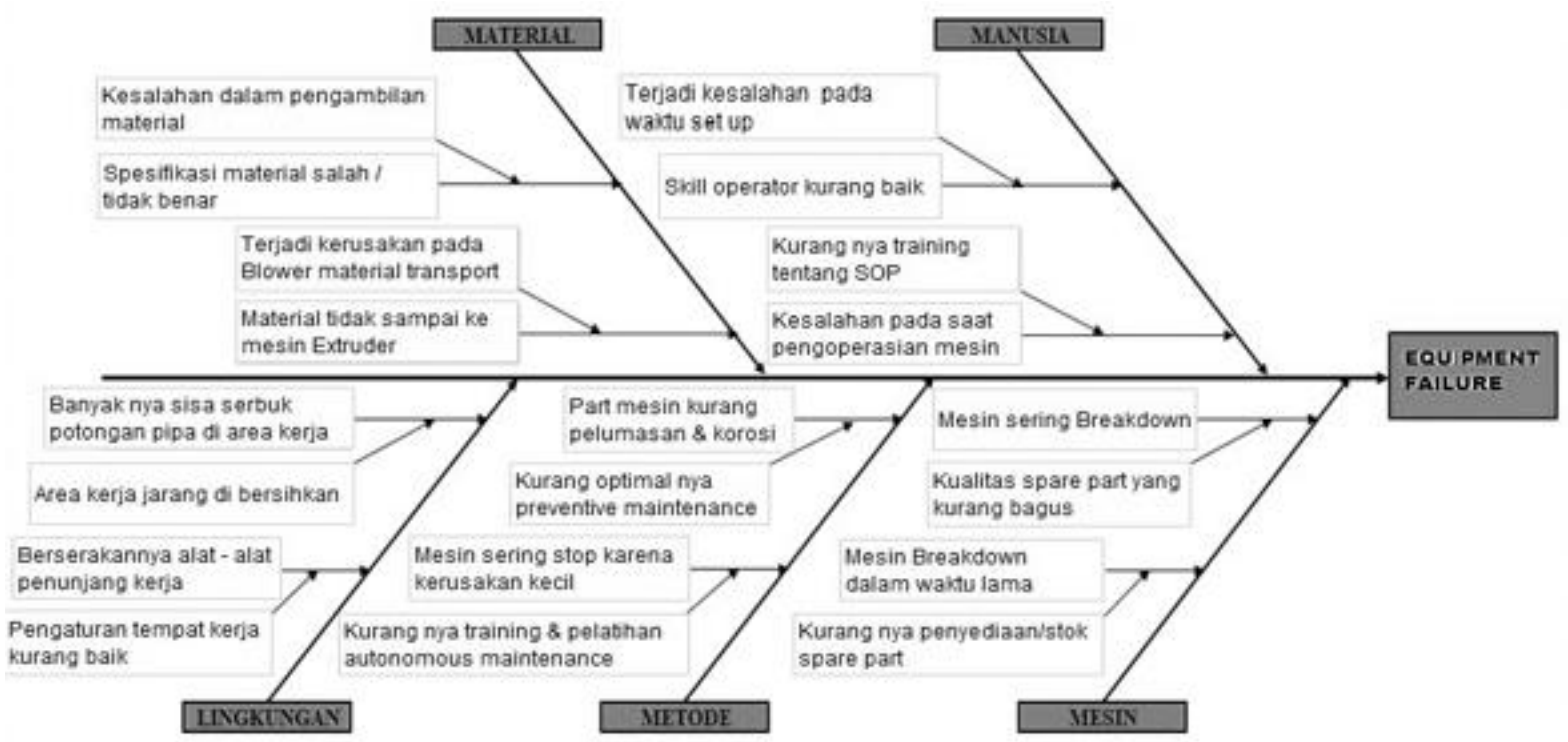

Gambar 3. Fishbone equipment failure

Berdasarkan gambar 3 bahwa untuk menentukan faktor sebab akibat equipment failure, dilakukan proses penilaian terhadap faktor-faktor yang berpengaruh dengan menggunakan angket penilaian oleh 5 tim penilai dengan hasil yang dijelaskan pada tabel 14 .

Tabel 14. Hasil diskusi fishbone equipment failure

\begin{tabular}{|c|c|c|c|c|c|c|c|}
\hline \multirow{2}{*}{ Faktor } & \multirow{2}{*}{ Penyebab } & \multicolumn{5}{|c|}{ Tim penilai } & \multirow{2}{*}{$\begin{array}{l}\text { Skor } \\
\text { nilai }\end{array}$} \\
\hline & & A & B & $\mathrm{C}$ & $\mathrm{D}$ & $\mathrm{E}$ & \\
\hline \multirow[b]{2}{*}{ 1. Manusia } & a. Terjadi kesalahan pada waktu set up & 3 & 1 & 1 & 5 & 1 & 11 \\
\hline & $\begin{array}{l}\text { b. Terjadi kesalahan pengoperasian } \\
\text { mesin }\end{array}$ & 1 & 1 & 3 & 1 & 3 & 9 \\
\hline \multirow[b]{2}{*}{ 2. Material } & a. Kesalahan pada pengambilan material & 3 & 1 & 1 & 3 & 1 & 9 \\
\hline & $\begin{array}{l}\text { b. Material tidak sampai ke mesin } \\
\text { extruder }\end{array}$ & 1 & 3 & 1 & 3 & 3 & 11 \\
\hline \multirow{2}{*}{ 3. Lingkungan } & a. Area kerja jarang dibersihkan & 3 & 1 & 1 & 3 & 3 & 11 \\
\hline & b. Berserakan alat-alat penunjang kerja & 1 & 3 & 3 & 1 & 1 & 9 \\
\hline \multirow{2}{*}{ 4. Metode } & $\begin{array}{l}\text { a. Autonomous maintenance belum } \\
\text { berjalan }\end{array}$ & 5 & 5 & 5 & 5 & 5 & 25 \\
\hline & $\begin{array}{l}\text { b. Preventive maintenance belum } \\
\text { optimal }\end{array}$ & 5 & 5 & 3 & 3 & 1 & 17 \\
\hline \multirow{2}{*}{ 5. Mesin } & a. Mesin sering breakdown & 3 & 3 & 3 & 1 & 1 & 11 \\
\hline & b. Mesin breakdown lama & 1 & 3 & 1 & 3 & 3 & 11 \\
\hline
\end{tabular}

Tabel 14 menunjukkan bahwa skor penilaian tertinggi adalah 25 dan 17 dan terdapat pada faktor metode, oleh karena itu tahap selanjutnya dilakukan usulan perbaikan dalam mengatasi equipment failure untuk meningkatkan efisiensi kinerja machine twin screw extruder PVC di PT. XYZ. 
A. Memberikan training ulang, penguatan dan peningkatan disiplin dalam implementasi $5 \mathrm{R}$ di dalam aktivitas produksi. Sehingga dengan peningkatan implementasi tersebut dalam membantu meningkatkan moral karyawan, memperkuat rasa memiliki terhadap mesin dan peralatan, mempermudah identifikasi masalah terkait mesin, peralatan, dan aspek operasional di lapangan.

B. Meningkatkan awareness terkait aspek perawatan mesin khususnya operator, dengan memberikan training atau pelatihan tentang autonomous maintenance kepada operator produksi.

C. Meningkatkan awareness penggunaan tag label personal autonomous maintenance untuk operator produksi agar operator produksi memahami status mesin, sekaligus dapat mempermudah team maintenance dalam mengidentifikasi masalah mesin/alat.

D. Memberikan training/pelatihan pemeliharaan mesin secara komprehensif bekerjasama dengan pihak produsen/principal mesin agar dapat menerapkan preventive \& predictive maintenance.

E. Membentuk team improvement/SGA/kaizen dengan dukungan pihak manajemen yang melibatkan pihak terkait seperti produksi, maintenance dan engineering, sehingga isu terkait mesin dapat ditangani dengan lebih baik dan melibatkan semua pihak.

\section{SIMPULAN}

Dari data-data produksi, diketahui bahwa selama proses produksi 12 bulan ditemukan banyaknya isu terkait quality dan rework, dengan temuan defect rata-rata $12 \%$, tingkat scrap rata-rata $2 \%$ dan tingkat rework rata-rata $6 \%$. Sedangkan dari hasil perhitungan nilai rata-rata OEE pada mesin twin screw extruder PVC di PT. XYZ adalah 63.10\%, angka ini masih jauh dari standar world class $85 \%$, dengan deviasi sekitar (21.90\%). Hal ini mengindikasikan masih adanya ruang improvement dan perbaikan yang harus dilakukan. Sedangkan dari indikator utama yang berpengaruh terhadap nilai OEE adalah equipment failure dengan kisaran 2502.50 jam dan dari hasil pembahasan terhadap fishbone analysis disimpulkan bahwa aspek metode merupakan yang paling berperan terhadap equipment failure tersebut sehingga disimpulkan bahwa perlunya usulan perbaikan guna memperbaiki tingkat OEE melalui; 1) Memberikan training ulang, penguatan dan peningkatan disiplin dalam implementasi 5R di dalam aktivitas produksi. Sehingga dengan peningkatan implementasi tersebut dalam membantu meningkatkan moral karyawan, memperkuat rasa memiliki terhadap mesin dan peralatan, mempermudah identifikasi masalah terkait mesin, peralatan dan aspek operasional di lapangan. 2) Meningkatkan awareness terkait aspek perawatan mesin khususnya operator, dengan memberikan training atau pelatihan tentang autonomous maintenance kepada operator produksi. 3) Meningkatkan awareness penggunaan tag label personal autonomous maintenance untuk operator produksi agar operator produksi memahami status mesin. Sekaligus hal ini dapat mempermudah tim maintenance dalam mengidentifikasi masalah mesin/alat. 4) Memberikan pelatihan pemeliharaan mesin secara komprehensif bekerjasama dengan pihak produsen/principal mesin agar dapat menerapkan preventive and predictive maintenance. 5) Membentuk team improvement/SGA/kaizen dengan dukungan pihak manajemen yang melibatkan pihak terkait seperti produksi, maintenance dan engineering. Sehingga isu terkait mesin dapat ditangani dengan lebih baik dan melibatkan semua pihak.

\section{REFERENSI}

[1] T. K. Agustiady and E. A. Cudney, "Total productive maintenance," Total Qual. Manag. Bus. Excell., 2018, doi: 10.1080/14783363.2018.1438843.

[2] V. Pascal, A. Toufik, A. Manuel, D. Florent, and K. Frédéric, "Improvement indicators for Total Productive Maintenance policy," Control Eng. Pract., 2019, doi: 10.1016/j.conengprac.2018.09.019. 
USULAN PERBAIKAN MELALUI PENERAPAN TOTAL PRODUCTIVE MAINTENANCE DENGAN METODE OEE PADA MESIN TWIN SCREW EXTRUDER PVC DI PT. XYZ

[3] K. Livia and P. D. Fewidarto, "Evaluasi Peningkatan Kinerja Produksi melaluiPenerapan Total Productive Maintenance di PTXacti Indonesia," J. Manaj. dan Organ., 2016, doi: 10.29244/jmo.v7i1.14067.

[4] J. R. Díaz-Reza, J. L. García-Alcaraz, and V. Martínez-Loya, Impact Analysis of Total Productive Maintenance. 2019.

[5] A. Wahid, "Penerapan Total Productive Maintenance (TPM)Produksi Dengan Metode Overall Equipment Effectiveness (OEE)Pada Proses ProduksiBotol (PT. XY Pandaan - Pasuruan)," J. Teknol. DAN Manaj. Ind., 2020, doi: 10.36040/jtmi.v6i1.2624.

[6] L. W. Hooi and T. Y. Leong, "Total productive maintenance and manufacturing performance improvement," J. Qual. Maint. Eng., 2017, doi: 10.1108/JQME-07-2015-0033.

[7] A. Rahman and S. Perdana, "ANALISIS PRODUKTIVITAS MESIN PERCETAKAN PERFECT BINDING DENGAN METODE OEE DAN FMEA,” J. Ilm. Tek. Ind., 2019, doi: 10.24912/jitiuntar.v7i1.5034.

[8] A. Rahman and S. Perdana, "Perhitungan Produktivitas Mesin Perfect Binding (Yoshino) dengan Menggunakan Metode Overall Equipment Effectiveness (OEE) pada PT. XYZ," STRING (Satuan Tulisan Ris. dan Inov. Teknol., 2018, doi: 10.30998/string.v3i1.2723.

[9] H. Suliantoro, N. Susanto, H. Prastawa, I. Sihombing, and A. Mustikasari, "PENERAPAN METODE OVERALL EQUIPMENT EFFECTIVENESS (OEE) DANFAULT TREE ANALYSIS (FTA) UNTUK MENGUKUR EFEKTIFITAS MESIN RENG,” J@ti Undip $J$. Tek. Ind., 2017, doi: 10.14710/jati.12.2.105-118.

[10] R. Domingo and S. Aguado, "Overall environmental equipment effectivenessas a metric of a lean and green manufacturing system," Sustain., 2015, doi: 10.3390/su7079031.

[11] R. Raguram, "Implementation of overall equipment effectiveness (OEE)," Middle - East J. Sci. Res., 2014, doi: 10.5829/idosi.mejsr.2014.20.05.11336.

[12] R. Hedman, M. Subramaniyan, and P. Almström, "Analysis of Critical Factors for Automatic Measurement of OEE," in Procedia CIRP, 2016, doi: 10.1016/j.procir.2016.11.023.

[13] T. Ylipää, A. Skoogh, J. Bokrantz, and M. Gopalakrishnan, "Identification of maintenance improvement potential using OEE assessment," Int. J. Product. Perform. Manag., 2017, doi: 10.1108/IJPPM-01-2016-0028.

[14] R. F. Prabowo, H. Hariyono, and E. Rimawan, "Total Productive Maintenance (TPM) pada Perawatan Mesin Grinding Menggunakan Metode Overall Equipment Effectiveness (OEE)," $J$. Ind. Serv., 2020, doi: 10.36055/jiss.v5i2.8001.

[15] N. Ahmad, J. Hossen, and S. M. Ali, "Improvement of overall equipment efficiency of ring frame through total productive maintenance: a textile case," Int. J. Adv. Manuf. Technol., 2018, doi: 10.1007/s00170-017-0783-2.

[16] R. M. Jannah, S. Supriyadi, and A. Nalhadi, "Analisis Efektivitas pada Mesin Centrifugal dengan Menggunakan Metode Overall Equipment Effectiveness (OEE)," in Prosiding Seminar Nasional Riset Terapan| SENASSET, 2017.

[17] D. H. Stamatis, The OEE primer: Understanding overall equipment effectiveness, reliability, and maintainability. 2017. 